DOI: 10.12731/2227-930X-2019-4-19-26

УДК 004.94

\title{
ПРОБЛЕМЫ УПРАВЛЕНИЯ РЕСУРСНЫМ ОБЕСПЕЧЕНИЕМ \\ В СИСТЕМАХ ПЕРЕВОЗОК С ПРИМЕНЕНИЕМ ОПТИМИЗАЦИОННО-ЭКСПЕРТНОГО МОДЕЛИРОВАНИЯ
}

\section{Львович Я.Е., Преображенский А.П., Чопоров О.Н.}

В данной статье рассматриваются вопросы, связанные с исследованием управления ресурсным обеспечением. В качестве основного подхода предлагается применять оптимизационно-экспертное моделирование.

Ключевые слова: система перевозок; ресурсное обеспечение; оптимизачия; моделирование; организация.

\section{PROBLEMS OF RESOURCE MANAGEMENT IN TRANSPORTATION SYSTEMS USING OPTIMIZATION AND EXPERT MODELING}

\section{Lvovich Ya.E., Preobrazhenskiy A.P., Choporov O.N.}

This paper discusses issues related to the study of resource management. As the main approach it is offered to apply optimization-expert modeling.

Ключевые слова: transportation system; resource provision; optimization; modeling; organization.

\section{Введение}

На основе мониторинга, осуществляемого в системах перевозок, есть возможности для того, чтобы решались соответствующие задачи $[1,2]$. Они связаны с тем, как осуществляются процессы управления, как формируется кадровый состав, как распределяются ресурсы в организациях-перевозчиках. Административное управление большей частью является основным. Оно использует- 
ся для того, чтобы управление было направлено на ресурсное обеспечение. Оно большей частью связано с бюджетными ресурсами.

Поддержка принятия решений для системы управления ресурсоэффективностью должна быть соответствующим образом осуществлена $[3,4]$. При этом должно быть применено многокритериальное оптимизационное моделирование [5, 6]. Кроме него необходимо использовать экспертное оценивание результатов. На основе указанных подходов можно проводить построение обобщенного критерия оптимизации. При этом обрабатывается мониторинговая информация. В ходе решения задачи исходят из применения схемы, на базе которых оценивается эффективность работы организаций-перевозчиков.

Если мы ориентируемся на административное управление ресурсным обеспечением в организациях-перевозчиках, то этого недостаточно для того, чтобы рациональным образом применять бюджетный ресурс. Чтобы принимаемые управленческие решения были более эффективны, перспективным представляется дополнение действующего контура управления контуром, в котором есть процедуры, позволяющие вести мониторинго-рейтинговое и оптимизационно-экспертное моделирование [7, 8].

\section{Описание подхода}

Ниже опишем, как решается задача по управлению ресурсным обеспечением. Рассматриваются системы перевозок при информационном мониторинге. При этом могут быть две возможности:

1. Использование обычных подходов;

2. Дополнение обычных подходов процедурами оптимизационно-экспертного моделирования. При этом можно говорить о том, что для управленческих решений есть интеллектуальная поддержка.

Есть ключевые механизмы в организациях-перевозчиках. За счет них бюджетные ресурсы эффективным образом управляются.

Также ресурсы рациональным образом будут распределены среди организаций-перевозчиков. Пусть есть задающие воздействия, когда описывается объект и система управления. Есть возможности по управленческим решениям. Они бывают двух типов: 
1. Значения объемов бюджетных средств. Они будут использоваться на то, чтобы реализовывать программы перевозок (R);

2. Потребности в обеспечении квалифицированными кадрами. Можно отметить их соотношение с направлениями и специальностями подготовок по двум уровням. Первый является федеральным $x_{j \phi}^{o}$ (j-являются номерами номенклатурных должностей, в рамках которых идет процесс подбора кадров, $j=\overline{1, J)}$. Второй является региональным $x_{j n}^{o}(n-$ является номером региона, $n=\overline{1, N})$.

Ресурс будет обычно переводиться в объемные характеристики $x_{i}(i=1, I)$ как некоторые заданные значения количества кадров по каждой из $i$-х организаций-перевозчиков. При этом должно быть обеспечено стабильное бюджетное финансирование по подведомственным организациям (рис. 1).

Если значения количества кадров выбираются в рамках конкурсной системы, то это определяет необходимость в совершенствовании схем, связанных с управлением объемными характеристиками. В качестве основы, для того, чтобы реализовать подобное управление, в таких случаях можно считать следующие характеристики:

1. Объемы предложений организации-перевозчика, связанных со значениями требуемого количества кадров на каждый класс номенклатурных должностей $x_{i j}^{0}(i=\overline{1 . J})$;

2. Значение потенциала организации-перевозчика $\pi_{i}(i=\overline{1, I})$ . Он будет определен в ходе соответствующих мониторинговых мероприятий. Их необходимо осуществить в течение некоторых календарных периодов.

Исходя из указанных характеристик можно сделать выбор по соответствующей расчетной схеме управления. Помимо этого необходимо сформулировать предложения. Они связаны с особенностями обеспечения сопровождения процессов распределения кадровых ресурсов в системах перевозок [9].

Подобная схема характерна тем, что в ней частичным образом есть влияние, связанное с ростом эффективности того, как осваивается бюджетный ресурс $R$.

Это выражается в том, что достигается максимальный объем средств, относящихся к предоставлению повышения квалифика- 
ции. Также управленческие решения могут поддерживаться за счет того, что организации-перевозчики группируются каким-то образом, но не всегда учитываются возможности оптимизации по объемным характеристикам внутри каждой организации.

В данной работе мы предлагаем помимо того, что есть расчетные процедуры расчета требуемого количества кадров в организациях-перевозчиках, использовать дополнительные процедуры по управлению. По федеральным и региональным уровням идет распределение объемных характеристик. При этом для них идет оптимальный выбор по организациям-перевозчикам.

За счет того, что включаются такие процедуры, можно проводить построение схемы управления. Для нее следует стремится к тому, чтобы развивать подсистему, связанная с поддержкой принятия решений. Тогда мониторинговая информация будет более эффективным образом применена [9].

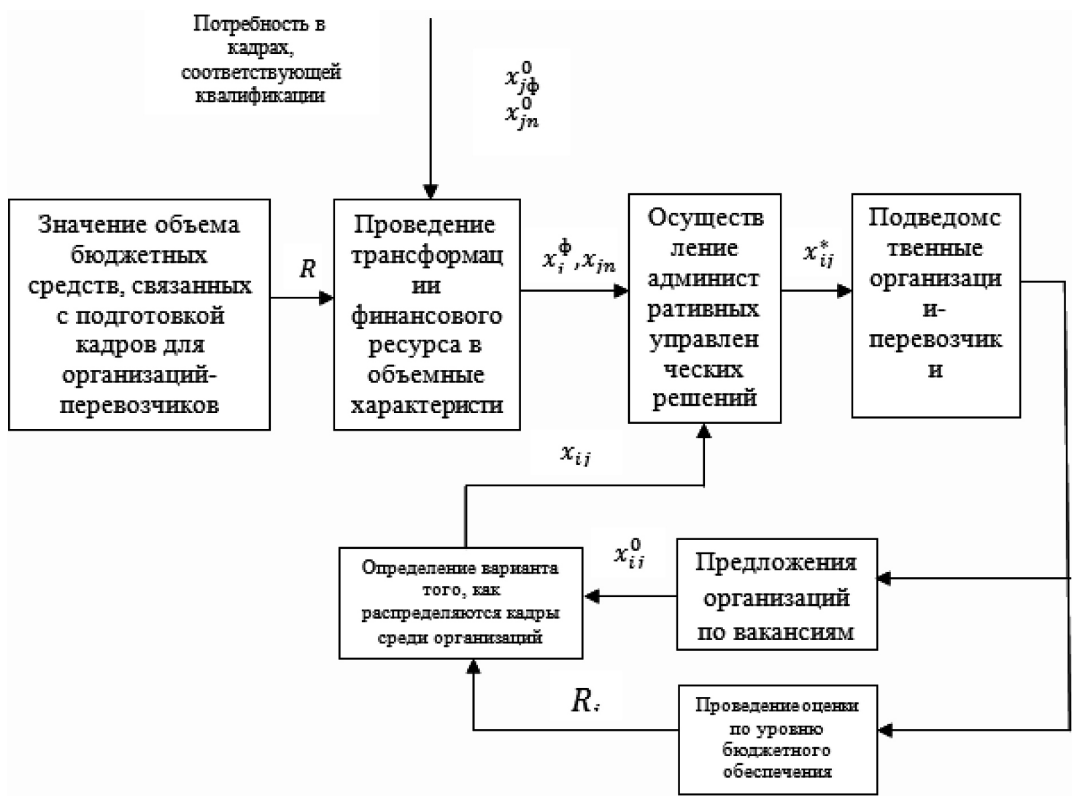

Рис. 1. Иллюстрация структурной схемы, связанной с обычным ресурсным обеспечением 
На рис. 2 приведена иллюстрация структурной схемы управления, использующая этот принцип.

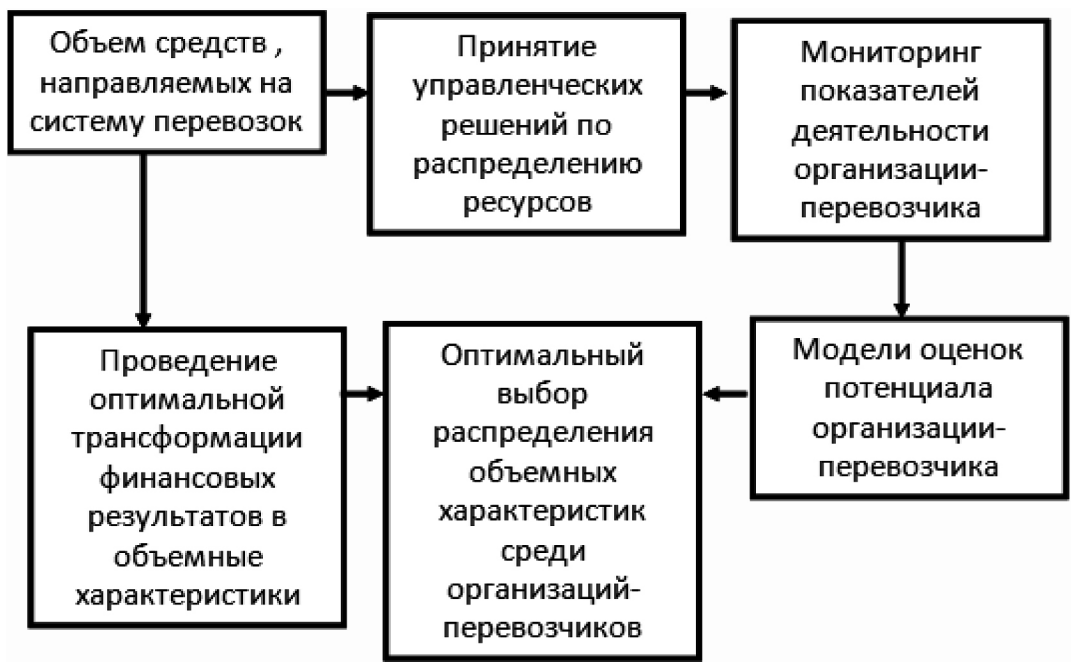

Рис. 1. Иллюстрация структурной схемы, позволяющей управлять ресурсными и объемными характеристиками в рамках систем перевозок

Чтобы схема была реализована, недостаточно применение известных методов. Необходимо, чтобы они были скомплексированы в рамках единой расчетной и экспертно-оптимизационной среды.

\section{Выводы}

Таким образом, в работе даны предложения по улучшению системы управления в системе организаций-перевозчиков. Повышение эффективности достигается за счет использования мониторинговой информации и моделей экспертных оценок и оптимизации.

Информация о конфликте интересов. Авторы заявляют об отсутствии конфликта интересов.

Информация о спонсорстве. Исследование не имело спонсорской поддержки. 


\section{Список литературы}

1. Юрочкин А.Г., Коростелева Н.А. Анализ особенностей управления и менеджмента в современных компаниях // Вестник Воронежского института высоких технологий. 2018. № 3(26). С. 78-80.

2. Гоян В.И., Никонова Е.3. Реинжиниринг и его место в жизненном цикле информационной системы // International Journal of Advanced Studies. 2019. T. 9. № 1-2. C. 45-51.

3. Калиберда Е.А., Христосова Н.Г. Автоматизация деятельности отдела доставки заказов интернет-магазина // International Journal of Advanced Studies. 2018. T. 8. № 1-2. С. 65-72.

4. Тюльпинова Н.В. Программный модуль для имитационного моделирования предприятий розничной торговли // International Journal of Advanced Studies. 2018. T. 8. № 1-2. C. 187-192.

5. Юрочкин А.Г., Коростелева Н.А. Вопросы обеспечения стратегического управления организации // Вестник Воронежского института высоких технологий. 2018. № 3(26). С. 135-138.

6. Львович И.Я. Львович Я.Е., Фролов В.Н. Информационные технологии моделирования и оптимизации: краткая теория и приложения / Воронеж: ИПЦ «Научная книга», 2016. 444 с.

7. Батищев Д.И., Львович Я.Е., Фролов В.Н. Оптимизация в САПР / М.: Высш.шк., 1977. 416 с.

8. Зазулин А.В., Преображенский Ю.П. Особенности построения семантических моделей предметной области // Вестник Воронежского института высоких технологий. 2008. № 3. С. 026-028.

9. Зяблов Е.Л., Преображенский Ю.П. Построение объектно-семантической модели системы управления // Вестник Воронежского института высоких технологий. 2008. № 3. С. 029-030.

\section{References}

1. Yurochkin A.G., Korosteleva N.A. Analiz osobennostej upravleniya i menedzhmenta v sovremennyh kompaniyah // Vestnik Voronezhskogo instituta vysokih tekhnologij. 2018. № 3(26). S. 78-80.

2. Goyan V.I., Nikonova E.Z. Reinzhiniring i ego mesto v zhiznennom cikle informacionnoj sistemy // International Journal of Advanced Studies. 2019. T. 9. № 1-2. S. 45-51. 
3. Kaliberda E.A., Hristosova N.G. Avtomatizaciya deyatel'nosti otdela dostavki zakazov internet-magazina // International Journal of Advanced Studies. 2018. T. 8. № 1-2. S. 65-72.

4. Tyul'pinova N.V. Programmnyj modul' dlya imitacionnogo modelirovaniya predpriyatij roznichnoj torgovli // International Journal of Advanced Studies. 2018. T. 8. № 1-2. S. 187-192.

5. Yurochkin A.G., Korosteleva N.A. Voprosy obespecheniya strategicheskogo upravleniya organizacii // Vestnik Voronezhskogo instituta vysokih tekhnologij. 2018. № 3(26). S. 135-138.

6. L'vovich I.Ya. L'vovich Ya.E., Frolov V.N. Informacionnye tekhnologii modelirovaniya i optimizacii: kratkaya teoriya i prilozheniya / Voronezh: IPC "Nauchnaya kniga", 2016. 444 s.

7. Batishchev D.I., L'vovich Ya.E., Frolov V.N. Optimizaciya v SAPR / M.: Vyssh.shk., 1977. 416 s.

8. Zazulin A.V., Preobrazhenskij Yu.P. Osobennosti postroeniya semanticheskih modelej predmetnoj oblasti // Vestnik Voronezhskogo instituta vysokih tekhnologij. 2008. № 3. S. 026-028.

9. Zyablov E.L., Preobrazhenskij Yu.P. Postroenie ob"ektno-semanticheskoj modeli sistemy upravleniya // Vestnik Voronezhskogo instituta vysokih tekhnologij. 2008. № 3. S. 029-030.

\section{ДАННЫЕ ОБ АВТОРАХ}

Львович Яков Евсеевич, профессор, доктор технических наук Воронежский государственный технический универсиmem

ул. 20 лет Октября, 84, г. Воронеж, 394006, Российская Федераиия

Komkovvivt@yandex.ru

Преображенский Андрей Петрович, профессор, доктор технических наук, доцент Воронежский институт высоких технологий ул. Ленина, 73а, Воронеж, 394043, Российская Федераџия Komkovvivt@yandex.ru 
Чопоров Олег Николаевич, профессор, доктор технических наук Воронежский государственный технический университет ул. 20 лет Октября, 84, г. Воронеж, 394006, Российская Федеращия

Komkovvivt@yandex.ru

\section{DATA ABOUT THE AUTHORS}

Lvovich Yakov Yevseevich, Professor, doctor of technical Sciences Voronezh State Technical University 84, 20 years of October Str., Voronezh, 394006, Russian Federation Komkovvivt@yandex.ru

ORCID: 0000-0002-7051-3763

Preobrazhenskiy Andrey Petrovich, professor, doctor of technical sciences, associate professor Voronezh Institute of High Technologies

73a, Lenin Str., Voronezh, 394043, Russian Federation Komkovvivt@yandex.ru ORCID: 0000-0002-6911-8053

Choporov Oleg Nikolaevich, Professor, doctor of technical Sciences Voronezh State Technical University 84, 20 years of October Str., Voronezh, 394006, Russian Federation Komkovvivt@yandex.ru

ORCID: 0000-0002-3176-499X 